\title{
Impact of quality of life on nutritional risk and malnutrition: a cross-sectional study in elderly patients
}

\author{
๑Duharrem Bayrak¹, @Gökhan Özpolat ${ }^{2}$ \\ ${ }^{1}$ Health Sciences University, Erzurum Regional Training and Research Hospital, Department of Internal Medicine, Erzurum, Turkey \\ ${ }^{2}$ Health Sciences University, Erzurum Regional Training and Research Hospital, Department of Psychiatry, Erzurum, Turkey
}

Cite this article as: Bayrak M, Özpolat G. Impact of quality of life on nutritional risk and malnutrition: a cross-sectional study in elderly patients. J Health Sci Med 2021; 4(6): 919-926.

\begin{abstract}
Objectives: To investigate prevalence of malnutrition and nutritional risk, related factors, and the association between nutritional status and quality of life in the elderly.

Material and Method: Cross-sectional study. Participants; elderly ( $\geq 65$ years) patients without severe hearing and vision impairment and dependency on a bed or wheel chair who admitted internal medicine outpatient clinics. Measurements; the mini nutritional assessment questionnaire, Charlson comorbidity index, the World Health Organization quality of life (WHOQOL-OLD) questionnaire. Intervention; none.

Results: The study included 532 patients with a mean age of 70.8 \pm 5.4 years. The median Mini Nutritional Assessment score was 26 , and the total prevalence of nutritional risk and malnutrition was $26.7 \%$. There were significant differences between the nutritional groups regarding the educational, living, and marital status, smoking history, presence of any systemic disease, Charlson Comorbidity Index, and polypharmacy $(\mathrm{p}<0.05)$. WHOQOL-OLD and its subdomain scores had a significant relationship with having nutritional risk or malnutrition $(\mathrm{p}<0.001)$. Total WHOQOL-OLD score and the Charlson Comorbidity Index were significant independent risk factors for developing nutritional risk and malnutrition.

Conclusion: Having nutritional risk or malnutrition in the elderly were significantly associated with the Charlson Comorbidity Index and the WHOQOL-OLD total and its subdomain scores.
\end{abstract}

Keywords: Elderly, nutritional status, malnutrition, health-related quality of life, comorbidity.

\section{INTRODUCTION}

The aging population has emerged as a new demographic trend in recent years. There is an inverse relationship between increased life expectancy and quality of life, most probably due to chronic diseases and disability $(1,2)$. Besides, a substantial proportion of communitydwelling elderly lacks an adequate nutrient intake leading to an increased risk for malnutrition $(1,3,4)$. Food is not only required for physiological well-being, but it also contributes to social, cultural, and psychological quality of life (4). So, aging and increased risk of malnutrition lead to a low quality of life as well as physical, mental, and social disabilities (5).

As a significant and common public health problem in older adults, the prevalence of malnutrition and associated factors show substantial variations based on the nutritional screening tools and the studied population's characteristics $(4,5)$. In previous studies, the rate of malnutrition ranged from 20 to $30 \%$ in clinical

settings and from 2 to $8 \%$ in older adults in communityresidences (2). Several physiological, socio-economic, and neuropsychological health-related factors influence the nutritional status, including depression, social isolation, and frailty status. Thus, the real-time knowledge about the prevalence of malnutrition in a specified population alerts the physicians dealing with older adults.

The assessment of nutritional risk is a strong determinant of interventions to prevent malnutrition and manage different aspects of quality of life, including its physical and mental components (1). Identifying people with malnutrition or nutritional risk includes some inherent difficulties (3). Besides the use of a diverse set of instruments for the evaluation of malnutrition and its risk, there is still a lack of a gold standard for the optimal definition of malnutrition. Nevertheless, the Mini Nutritional Assessment (MNA) has been recommended for its higher efficiency to predict malnutrition in the elderly $(6,7)$. 
In this study, we aimed to determine the prevalence of malnutrition and associated factors and analyze the association between the nutritional status of the older adults indicated by the MNA and their quality of life indicated by the World Health Organization Quality of Life (WHOQOL-OLD) questionnaire.

\section{MATERIAL AND METHOD}

The study was carried out with the permission of Erzurum Regional Training and Researh Hospital Clinical Researchs Ethics Committee (Date: 06.01.2020, Decision No: 2020/01-06). All procedures were carried out in accordance with the ethical rules and the principles of the Declaration of Helsinki.

\section{Patients}

The MNA questionnaire was applied to all consecutive patients who were 65 or older and admitted to the Internal Medicine Outpatient Clinics after obtaining their consent between 01.01.2020 and 01.07.2020. Patients who had communication problems such as severe hearing $(\mathrm{n}=235)$ and vision impairment $(\mathrm{n}=192)$ or were dependent on bed or wheelchair $(n=59)$ were not evaluated. A total of 532 patients were included in the study.

Several sociodemographicand clinicalvariables, including age, sex, body mass index (BMI), educational and marital status, living status (alone, with relatives, or residential care center), history of smoking, comorbidities, and drugs used, were evaluated. The patients were classified based on BMI values as underweight $(\mathrm{BMI}<18.5 \mathrm{~kg} / \mathrm{m} 2)$, normal (18.5-24.9 kg/m2), or overweight (BMI $\geq 25 \mathrm{~kg} /$ $\mathrm{m} 2$ ). Patients using five or more drugs were grouped as polypharmacy. The Charlson Comorbidity Index (CCI) was calculated for each patient using the website www. mdcalc.com/charlson-comorbidity-index (8).

\section{Questionnaires and Scales}

Nutritional status was evaluated using the MNA questionnaire that was translated and validated in the Turkish language (9). MNA includes 18 items for the anthropometric measurements, dietary intake, global health assessment, and self-assessment of health and nutrition. The patients were categorized as satisfactory nutritional status (scores $\geq 24$ ), nutritional risk (scores between 17 and 23.5), and malnutrition (scores <17) (1).

The WHOQLD-OLD questionnaire was applied to the patients to assess their quality of life. The WHOQLDOLD contains six different subdomains: sensory abilities, autonomy, past, present, future activities, social participation, death and dying, and intimacy (1). Higher scores represent a higher self-rated quality of life. The 30-item Geriatric Depression Scale (GDS) was used to evaluate depression. A GDS score $>10$ was regarded as depression $(10,11)$. Cognitive ability was assessed using the Mini-Mental State Examination (MMSE), commonly used to monitor dementia and cognitive states $(12,13)$. The MMSE score ranges from 0 (impaired) to 30 (normal). Scores below 24 were regarded as cognitive impairment (14). The Hendrich II Fall Risk Model (HIIFRM) was used to analyze the factors associated with fall risk. The HIIFRM score ranges from 0 to 16 , where scores $\geq 5$ were considered a high risk for falls (15).

\section{Anthropometric Measurements}

The anthropometric evaluation included body circumference (calf, arm) and triceps skinfold thickness. All measurements were carried out in the morning after an overnight fast of at least 8 hours. The BMI values were calculated as the bodyweight divided by the square of the height $(\mathrm{kg} / \mathrm{m} 2)$. The calf and arm circumferences were measured using a non-elastic tape measure. For calf measurements, the tape measure was placed around the calf without compressing the subcutaneous tissue and was moved along the calf's length to obtain the maximal circumference while the patient was lying down, and the leg was angled $90^{\circ}$ at the knee. Calf circumference values were recorded as the average of the measurements from two trials for each leg, which were averaged again to get the overall measurement (16). Forearm circumference (mid-upper arm circumference) was measured at the midpoint between the acromion and olecranon bones while the arm was angled $90^{\circ}$ at the elbow (17). For the measurement of triceps skinfold thickness, while the patients were standing and the arms were free at both sides, the arms were angled $90^{\circ}$, and the midpoint between the shoulder and the acromion was marked with a pencil. The skinfold was measured at the marked point. The anthropometric measurements were performed twice by experienced nurses and averaged later.

Biochemical analyses included hemoglobin $(\mathrm{g} / \mathrm{dL})$, fasting blood glucose (mg/dL), HbAlc (\%), total cholesterol (mg/dL), low density lipoprotein (LDL) cholesterol $(\mathrm{mg} / \mathrm{dL})$, triglyceride $(\mathrm{mg} / \mathrm{dL})$, albumin $(\mathrm{mg} /$ $\mathrm{dL})$, ferritin $(\mathrm{ng} / \mathrm{mL})$, vitamins B12 $(\mathrm{pg} / \mathrm{mL})$ and D $(\mathrm{ng} /$ $\mathrm{mL}$ ) and B9 (folic acid) (ng/mL). Glomerular filtration rate $(\mathrm{mL} / \mathrm{min})$ was calculated using the Modification of Diet in Renal Disease (MDRD) formula (18).

\section{Statistical Analysis}

The primary outcome of the study was the prevalence of nutritional risk and malnutrition. The analysis of the factors associated with nutritional risk and malnutrition and the association between nutritional risk and the quality of life were the secondary outcomes.

Descriptive statistics were given as mean \pm standard deviation or median [interquartile range-IQR] for the continuous variables depending on their distribution. 
Numbers and percentages were used for categorical variables. The Kolmogorov-Smirnov test was used to check normal distribution. The One-Way ANOVA test was used to compare more than two independent groups when the numerical variables had a normal distribution. For variables without normal distribution, the KruskalWallis test was applied.

For the analyses in which non-parametric tests were used, the differences between the groups were evaluated with the Tukey test when data was homogeneous based on its distribution. The Games-Howell test was used in situations where data was not homogeneous. The Dwass-SteelCritchlow-Fligner test was used to evaluate the differences between the groups. To compare the differences between categorical variables, Pearson Chi-Square and FisherFreeman-Halton tests were used in $2 \times 2$ tables. Spearman correlation coefficients were calculated to analyze the relationships between numerical variables. Univariate and multivariate logistic regression analyses were performed to analyze the demographic and clinical factors that impact nutritional risk and malnutrition. Statistically significant demographic and clinical characteristics in the univariate analysis were included in the multivariate analysis. For statistical analysis and figures, Jamovi (version 1.6.3, retrieved from https://www.jamovi.org) and JASP (version 0.13.1, retrieved from https://jasp-stats.org) software were used. The significance level ( $\mathrm{p}$-value cutoff) was set at 0.05 in all statistical analyses.

\section{RESULTS}

There were 532 patients with a mean age of $70.8 \pm 5.4$ years. The female to male ratio was 1.1. The majority of the patients lived with their relatives. Although hypertension was the most significant comorbid disease (358 patients, $67.3 \%)$, there was no comorbidity in 249 patients (46.8\%). The median CCI score was 4 . The demographic and clinical characteristics of the study group were given in Table 1.

Table 1. Demographic and clinical characteristics of the study groups

\begin{tabular}{|c|c|c|c|c|c|}
\hline & \multirow[b]{2}{*}{$\begin{array}{l}\text { Overall } \\
(n=532)\end{array}$} & \multicolumn{3}{|c|}{ Groups } & \multirow[b]{2}{*}{ p-values } \\
\hline & & $\begin{array}{l}\text { Satisfactory nutritional } \\
\text { status }(n=390)\end{array}$ & $\begin{array}{c}\text { Nutritional risk } \\
(\mathbf{n}=83)\end{array}$ & $\underset{(n=59)}{\text { Malnutrition }}$ & \\
\hline Age $(\text { year })^{\dagger}$ & $70.8 \pm 5.4$ & $70.7 \pm 5.4$ & $70.9 \pm 6.0$ & $71.4 \pm 4.4$ & 0.514 \\
\hline $\operatorname{Sex}^{\ddagger}$ & & & & & 0.938 \\
\hline Male & $253(47.6)$ & $187(47.9)$ & $38(45.8)$ & $28(47.5)$ & \\
\hline Female & $279(52.4)$ & $203(52.1)$ & $45(54.2)$ & $31(52.5)$ & \\
\hline Educational status ${ }^{\ddagger}$ & & & & & $<0.001$ \\
\hline Illiterate & $125(23.5)$ & $69(17.7)^{\mathrm{a}}$ & $28(33.7)^{\mathrm{b}}$ & $28(47.5)^{b}$ & \\
\hline Primary & $307(57.7)$ & $230(59.0)^{\mathrm{a}}$ & $46(55.4)^{\mathrm{a}}$ & $31(52.5)^{\mathrm{a}}$ & \\
\hline Secondary-college & $76(14.3)$ & $67(17.2)^{\mathrm{a}}$ & $9(10.8)^{\mathrm{a}}$ & $0(0.0)^{\mathrm{b}}$ & \\
\hline University & $24(4.5)$ & $24(6.2)^{\mathrm{a}}$ & $0(0.0)^{\mathrm{b}}$ & $0(0.0)^{\mathrm{a}, \mathrm{b}}$ & \\
\hline Living status ${ }^{\ddagger}$ & & & & & $<0.001$ \\
\hline Alone & $136(25.6)$ & $88(22.6)^{\mathrm{a}}$ & $33(39.8)^{b}$ & $15(25.4)^{\mathrm{a}, \mathrm{b}}$ & \\
\hline With relatives & $344(64.7)$ & $291(74.6)^{\mathrm{a}}$ & $45(54.2)^{\mathrm{b}}$ & $8(13.6)^{c}$ & \\
\hline Residential care center & $52(9.8)$ & $11(2.8)^{\mathrm{a}}$ & $5(6.0)^{\mathrm{a}}$ & $36(61.0)^{\mathrm{b}}$ & \\
\hline Marital status $s^{\ddagger}$ & & & & & $<0.001$ \\
\hline Single & $38(7.1)$ & $28(7.2)^{\mathrm{a}}$ & $5(6.0)^{\mathrm{a}}$ & $5(8.5)^{\mathrm{a}}$ & \\
\hline Married & $333(62.6)$ & $289(74.1)^{\mathrm{a}}$ & $40(48.2)^{b}$ & $4(6.8)^{c}$ & \\
\hline Divorced/widowed & $161(30.3)$ & $73(18.7)^{\mathrm{a}}$ & $38(45.8)^{b}$ & $50(84.7)^{c}$ & \\
\hline Smoking ${ }^{*}$ & $208(39.1)$ & $145(37.2)^{\mathrm{a}}$ & $30(36.1)^{\mathrm{a}}$ & $33(55.9)^{b}$ & 0.019 \\
\hline \multicolumn{6}{|l|}{ Comorbidity } \\
\hline Hypertension & $358(67.3)$ & $239(61.3)^{\mathrm{a}}$ & $62(74.7)^{\mathrm{b}}$ & $57(96.6)^{c}$ & $<0.001$ \\
\hline Diabetes mellitus & $210(39.5)$ & $149(38.2)$ & $37(44.6)$ & $24(40.7)$ & 0.548 \\
\hline Any systemic disease & $283(53.2)$ & $172(44.1)^{\mathrm{a}}$ & $54(65.1)^{\mathrm{b}}$ & $57(96.6)^{c}$ & $<0.001$ \\
\hline Systemic disease $e^{\ddagger}$ & & & & & $<0.001$ \\
\hline Absent & $249(46.8)$ & $218(55.9)^{\mathrm{a}}$ & $29(34.9)^{b}$ & $2(3.4)^{\mathrm{c}}$ & \\
\hline Coronary artery disease & $84(15.8)$ & $66(16.9)^{a}$ & $14(16.9)^{\mathrm{a}, \mathrm{b}}$ & $4(6.8)^{\mathrm{b}}$ & \\
\hline Chronic heart failure & $17(3.2)$ & $10(2.6)^{\mathrm{a}}$ & $5(6.0)^{\mathrm{a}}$ & $2(3.4)^{\mathrm{a}}$ & \\
\hline Chronic renal failure & $40(7.5)$ & $34(8.7)^{\mathrm{a}}$ & $4(4.8)^{\mathrm{a}}$ & $2(3.4)^{\mathrm{a}}$ & \\
\hline Cerebrovascular accident & $66(12.4)$ & $18(4.6)^{\mathrm{a}}$ & $11(13.3)^{\mathrm{b}}$ & $37(62.7)^{\mathrm{c}}$ & \\
\hline Chronic liver failure & $10(1.9)$ & $7(1.8)^{\mathrm{a}}$ & $1(1.2)^{\mathrm{a}}$ & $2(3.4)^{\mathrm{a}}$ & \\
\hline Malignancy & $23(4.3)$ & $6(1.5)^{\mathrm{a}}$ & $11(13.3)^{b}$ & $6(10.2)^{b}$ & \\
\hline Chronic obstructive pulmonary disease & $43(8.1)$ & $31(7.9)^{\mathrm{a}}$ & $8(9.6)^{a}$ & $4(6.8)^{\mathrm{a}}$ & \\
\hline Charlson comorbidity index ${ }^{\beta}$ & $4.0[2.0-14.0]$ & $4.0[2.0-10.0]^{\mathrm{a}}$ & $5.0[3.0-13.0]^{\mathrm{b}}$ & $8.0[4.0-14.0]^{\mathrm{c}}$ & $<0.001$ \\
\hline Polypharmacy ${ }^{\ddagger}$ & $215(40.4)$ & $121(31.0)^{\mathrm{a}}$ & $42(50.6)^{\mathrm{b}}$ & $52(88.1)^{c}$ & $<0.001$ \\
\hline Mini Nutritional Assessment ${ }^{\beta}$ & $26.0[6.0-29.0]$ & $26.0[19.0-29.0]^{\mathrm{a}}$ & $19.0[11.0-26.0]^{\mathrm{b}}$ & $9.0[6.0-17.0]^{\mathrm{c}}$ & $<0.001$ \\
\hline
\end{tabular}


The median MNA score was 26 [6-29]. Based on the MNA scores, 83 patients (15.6\%) had nutritional risk, and 59 patients (11.1\%) had malnutrition; 390 patients (73.3\%) had satisfactory nutritional status. The combined prevalence of malnutrition (nutritional risk and malnutrition) was $26.7 \%$. The comparison of different nutritional status (satisfactory nutritional status, nutritional risk, and malnutrition) for various variables was given in Table 1. Significant differences were found between the groups regarding their education, living and marital status, smoking history, systemic diseases, CCI scores, and polypharmacy status. Malnutrition was more common in patients with low education, those living in residential care centers, and those who were divorced or widowed ( $\mathrm{p}<0.001$ for each). Smoking was significantly associated with malnutrition $(\mathrm{p}=0.019)$. Hypertension and any systemic disease were more common in patients with nutritional risk and malnutrition $(\mathrm{p}<0.001$ for both). Cerebrovascular accident was the most common systemic disease $(62.7 \%)$ in the patients with malnutrition $(\mathrm{p}<0.001)$. The CCI score was significantly higher in malnourished patients $(\mathrm{p}<0.001)$. Polypharmacy was more frequent in the patients with malnutrition $(88.1 \%)$ than in the patients with nutritional risk (50.6\%) and satisfactory nutritional status (31.0\%).

Outcomes of the questionnaires, anthropometric measurements, and laboratory analyses were summarized in Table 2. The median total WHOQOL-OLD scores were $27.0,36.0$, and 56.0 in patients with malnutrition, nutritional risk, and satisfactory nutritional status, respectively; the differences between the groups were significant $(\mathrm{p}<0.001$ for all). The WHOQOL-OLD and its domain scores were significantly associated with nutritional risk and malnutrition. There were significant differences between the groups regarding all subdomain scores of the WHOQOL-OLD $(\mathrm{p}<0.001)$. The rates of

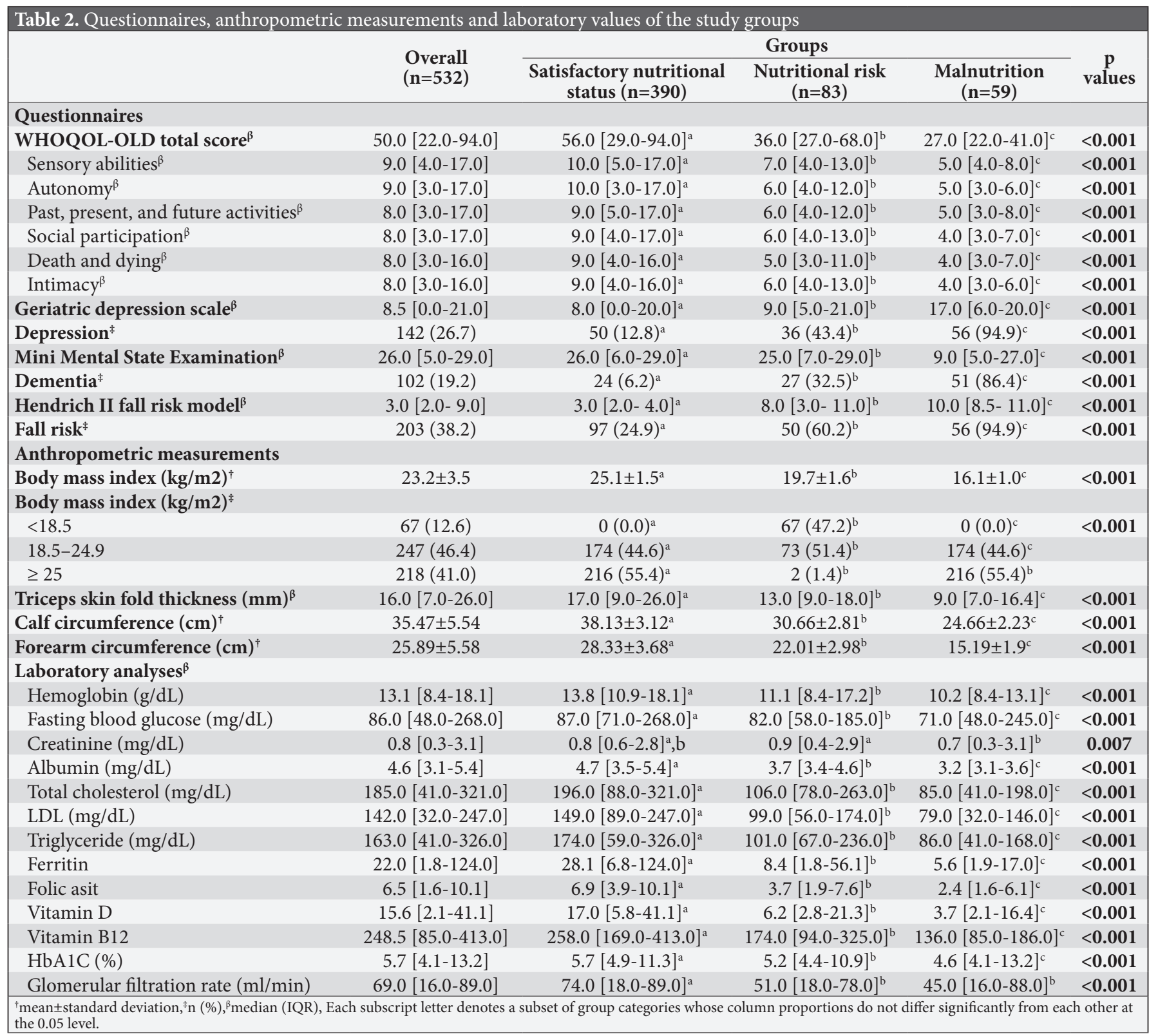


depression, dementia, and fall risk were significantly higher in patients with nutritional risk and malnutrition (Table 2). We also detected significant differences between the groups in terms of the anthropometric measurements, including BMI, BMI category, triceps skinfold thickness, the calf and forearm circumferences, and laboratory parameters (Table 2).

There were significant correlations between the MNA score and total WHOQOL-OLD and subdomain scores (Table 3). Increased MNA scores (indicating a satisfactory nutritional status) were associated with increased scores in WHOQOL-OLD and its subdomain (indicating a higher quality of life). Besides, a positive correlation was found between the MNA and MMSE scores $(r=0.545$, $\mathrm{p}<0.001)$ while there were negative correlations between the MNA score and the GDS and HIIFRM scores ( $r=-$ $0.462, \mathrm{r}<0.001$ and $\mathrm{r}=-0.380, \mathrm{p}<0.001$, respectively).

Univariate and multivariate logistic regression analyses of the variables for nutritional risk and malnutrition were given in Table 4. Most of the independent variables were

Table 3. Correlation of Mini Nutritional Risk Assessment with patient reported outcomes and WHOQOL-OLD score

\begin{tabular}{|lcc|}
\hline & \multicolumn{2}{c}{ Mini nutritional assessment } \\
\cline { 2 - 3 } & $\mathbf{r}$ & $\mathbf{p}$ \\
\hline Geriatric Depression Scale & -0.462 & $<\mathbf{0 . 0 0 1}$ \\
Mini Mental State Examination & 0.545 & $<\mathbf{0 . 0 0 1}$ \\
Hendrich II fall risk model & -0.380 & $<\mathbf{0 . 0 0 1}$ \\
WHOQOL-OLD total score & 0.693 & $<\mathbf{0 . 0 0 1}$ \\
Sensory abilities & 0.673 & $<\mathbf{0 . 0 0 1}$ \\
Autonomy & 0.683 & $<\mathbf{0 . 0 0 1}$ \\
Past, present, and future activities & 0.654 & $<\mathbf{0 . 0 0 1}$ \\
Social participation & 0.666 & $<\mathbf{0 . 0 0 1}$ \\
Death and dying & 0.677 & $<\mathbf{0 . 0 0 1}$ \\
Intimacy & 0.641 & $<\mathbf{0 . 0 0 1}$ \\
\hline
\end{tabular}

significantly associated with nutritional risk according to the univariate analysis (Table 4). Multivariate logistic regression analysis showed that total WHOQOL-OLD score $(\mathrm{OR}=1.40, \mathrm{CI} 95 \%: 1.30-1.52, \mathrm{p}<0.001)$ and CCI score $(\mathrm{OR}=1.73$, CI 95\%:1.34-2.23, $\mathrm{p}<0.001)$ were the significant independent risk factors for the development of nutritional risk and malnutrition.

\section{DISCUSSIONS}

In the present study, we showed significant associations between malnutrition risk and quality of life. Besides, meaningful relationships between the MNA score and depression, cognitive impairment, and a higher fall risk were also detected in older adults. As one of the first studies focusing on evaluating the association between quality of life and nutritional risk in Turkish elderly patients, the overall prevalence of nutritional risk and malnutrition was relatively high. Nutritional status and quality of life in elderly patients were regarded as the indicators for each other.

Depending on the study groups' characteristics and the country of the study, reported prevalence of nutritional risk and malnutrition shows significant variation. The combined rates of nutritional risk and malnutrition (based on the MNA scores) range from $14.3 \%$ to $82.6 \%$ $(1,4,5,7,19-22)$. Several factors have been speculated to explain these variations. Living in institutions with menus for three meals that may lack essential nutrients was regarded as an underlying factor (22). Extended family support was suggested as another factor; for example, living in crowded families prevents loneliness and social isolation (4). In our study, the combined malnutrition risk was the highest among the patients living in residential care centers and the lowest in

Table 4. Univariate and multivariate logistic regression analyses of the variables for the development of nutritional risk and malnutrition

\begin{tabular}{|c|c|c|c|c|}
\hline & \multicolumn{2}{|c|}{ Univariate } & \multicolumn{2}{|c|}{ Multivariate } \\
\hline & $\begin{array}{c}\text { Crude OR } \\
{[95 \% \mathrm{CI}]}\end{array}$ & $\begin{array}{c}\text { crude } \\
\text { p value }\end{array}$ & $\begin{array}{c}\text { Adjusted OR } \\
{[95 \% \mathrm{CI}]}\end{array}$ & $\begin{array}{l}\text { crude } \\
\text { p value }\end{array}$ \\
\hline Age & $1.02[0.98-1.05]$ & 0.397 & - & - \\
\hline Sex: Female vs. male & $1.06[0.72-1.56]$ & 0.764 & - & - \\
\hline Educational status: Ref. literate (primary+secondary-college+university) vs. illiterate & $3.03[1.98-4.64]$ & $<0.001$ & $0.68[0.32-1.43]$ & 0.308 \\
\hline \multicolumn{5}{|c|}{ Living status: Ref. relatives } \\
\hline Alone & $2.99[1.90-4.73]$ & $<0.001$ & $0.58[0.14-2.37]$ & 0.447 \\
\hline Residential care center & $0.15[0.07-0.31]$ & $<0.001$ & $1.14[0.38-3.42]$ & 0.813 \\
\hline Marital status: Ref. married with single+divorced/widowed & $6.37[4.18-9.72]$ & $<0.001$ & $2.13[0.53-8.49]$ & 0.285 \\
\hline Smoking: Present vs. absent & $1.35[0.91-1.99]$ & 0.134 & - & - \\
\hline Comorbidity: Present vs. absent & $0.06[0.01-0.24]$ & $<0.001$ & $2.15[0.13-35.43]$ & 0.592 \\
\hline Hypertension: Present vs. absent & $0.31[0.19-0.50]$ & $<0.001$ & $1.44[0.62-3.37]$ & 0.400 \\
\hline Charlson comorbidity score & $0.56[0.50-0.62]$ & $<0.001$ & $1.73[1.34-2.23]$ & $<0.001$ \\
\hline WHOQOL-OLD total score & 1.24 [1.19-1.29] & $<0.001$ & $1.40[1.30-1.52]$ & $<0.001$ \\
\hline Depression: Present vs. absent & $0.08[0.05-0.13]$ & $<0.001$ & $1.17[0.40-3.42]$ & 0.770 \\
\hline Dementia: Present vs. absent & $0.05[0.03-0.09]$ & $<0.001$ & $0.53[0.15-1.86]$ & 0.322 \\
\hline Fall risk: Present vs. absent & $0.11[0.07-0.17]$ & $<0.001$ & $1.88[0.76-4.61]$ & 0.171 \\
\hline
\end{tabular}

OR: odds ratio, CI: confidence interval 
patients living with relatives. Evaluation of these factors in a homogenous manner may not help reach a definitive conclusion; therefore, the complexity of the problem may necessitate prospective large-scale studies.

The general health status of elderly patients is a critical variable that predicts the nutrition risk. Coexisting diseases and their related indexes such as the CCI and the use of multiple medications (polypharmacy) might be used as the indicators for this purpose $(3,7)$. Polypharmacy may have a negative impact on nutritional status due to drug-food interactions or gastrointestinal complaints $(3,7)$. Our results were consistent with these studies. The presence of multiple comorbidities has been speculated as a significant risk factor for malnourishment in elderly patients (23). Although the relationship between comorbidities and malnutrition remains obscure, it has been thought that these comorbidities may have a negative impact on the nutritional status of the patients. In association with polypharmacy, comorbidities, as reflected by the CCI in the present study, may be regarded as indicators for developing malnutrition. Therefore, those who provide care for elderly patients are recommended to pay attention to the presence or absence of such factors because of their close association with malnutrition.

The educational, marital, and living status are thought to impact the nutritional quality of older adults significantly $(1,7)$. Living alone or widowed older men are more vulnerable to nutritional risk because of difficulty buying and preparing food (1). In this study, we found that elderly illiterate, divorced, or widowed people living alone or in residential care centers were the riskiest group for malnutrition (4). The lower level of education was significantly associated with malnutrition (23). Sex discrepancy in nutrition is regarded as a complex and poorly understood issue (3). Some researchers reported that female sex is an independent risk factor for developing poor nutritional status, but we did not find any association between sex and nutrition $(3,5,6)$. These controversial results might be affected by multiple unidentified confounders among the patients' demographic and clinical characteristics (4). Therefore, reciprocal associations of several demographic and clinical features should be considered while evaluating these findings.

The association between the presence or severity of depression and nutritional status was also investigated. There was a significant negative correlation between the GDS and MNA scores in the present study. In the BRIGHT trial, patients with more depressive symptoms were at moderate or high risk of malnutrition (3). In previous studies, nutritional disorders and malnutrition are regarded as modifiable risk factors for preventing and progression of age-related cognitive impairment (24-26). It was also mentioned that there was a relationship between malnutrition and the severity of cognitive impairment and that good nutritional status is associated with normal cognition. In this study, we showed a significant positive correlation between the MMSE and MNA scores. Poor nutritional status has been speculated as a significant factor for falls, especially in elderly patients, based on communitybased studies (27). As opposed to our findings, Adly et al. (27) demonstrated a significant association between malnutrition and fall risk assessment scores using various scales. In light of this evidence, we may conclude that poor nutritional status in the elderly may reflect many underlying problems, such as impaired motor function, psychological abnormalities, and cognitive and functional impairment. So, efforts should be made to improve nutritional status considering these outcomes, especially in the elderly.

The strongest associations between nutritional risk and the physical health and sensory abilities subdomains of the WHOQOL-OLD scale has been reported in previous studies $(1,3,5)$. Physical health status may be regarded as a critical factor for routine daily activities such as eating and walking; however, close associations between the other domains are also possible (1). Sensory abilities such as sight, touch, smell, and taste may also impact both malnutrition and the quality of life. Our study showed that the total WHOQOL-OLD score and all subdomain scores were significantly correlated with the risk of malnutrition, as opposed to findings in other studies (3). Some studies have also reported similar findings (1). Using several scales for quality of life, other studies have shown that mental and physical components had a critical impact on nutritional status $(7,19)$. Therefore, we may conclude that older adults' nutritional status may be directly related to all aspects of the quality of life, and the elderly individuals with nutritional risk are more likely to score lower on all or some domains of quality of life scales.

Considering the study's limitations, there may be controversial cause-and-effect relationships between the primary outcomes of the risk of malnutrition and the quality of life. Besides, the inclusion of only the patients admitted to the outpatient clinics was regarded as another limitation. Causality of the associated variables were lacked due to the cross-sectional design of the study. It is better to assess the likelihood of adverse causality and temporal relationships between quality of life, malnutrition risk, and other relevant variables. On the other hand, the present study had several important strengths, including the use of MMSE, GDS, and HIIFRM. 


\section{CONCLUSION}

The prevalence of nutritional risk and malnutrition was high among elderly patients. The study also showed how various demographic and clinical factors were associated with malnutrition or nutritional risk. Nutritional risk and malnutrition were associated with the total WHOQOL-OLD score and the CCI score. Besides, there were significant correlations between all subdomains of the WHOQOL-OLD questionnaire and malnutrition. Having poor quality of life and higher comorbidities were the main determinants of malnutrition and nutritional risk in the multivariate analysis. The present findings contribute to the understanding of nutritional risk and its potential determinants. Results also underline the association between quality of life and nutritional status. These findings may help prevent nutritional risk and determine appropriate interventions, especially for the elderly population.

\section{Clinical Implications}

The combined prevalence of nutritional risk and malnutrition was $26.7 \%$ in the elderly patients.

There were significant correlations between all subdomains of the WHOQOL-OLD questionnaire and malnutrition and nutritional risk assessed with MNA.

Rates of depression, dementia, and fall risk were significantly higher in patients with nutritional risk and malnutrition.

Nutritional risk and malnutrition were significantly associated with the WHOQOL-OLD and CCI scores. Having poor quality of life and higher comorbidities were the main determinants of malnutrition and nutritional risk in the multivariate analysis.

\section{ETHICAL DECLARATIONS}

Ethics Committee Approval: The study was carried out with the permission of Erzurum Regional Training and Researh Hospital Clinical Researchs Ethics Committee (Date: 06.01.2020, Decision No: 2020/01-06).

Informed Consent: All patients signed the free and informed consent form.

Referee Evaluation Process: Externally peer-reviewed.

Conflict of Interest Statement: The authors have no conflicts of interest to declare.

Financial Disclosure: The authors declared that this study has received no financial support.

Author Contributions: All of the authors declare that they have all participated in the design, execution, and analysis of the paper, and that they have approved the final version.

\section{REFERENCES}

1. Damião R, Meneguci J, da Silva Santos, Matijasevich A, Rossi Menezes P. Nutritional Risk and Quality of Life in CommunityDwelling Elderly. A Cross-Sectional Study. J Nutr Heal Aging 2018; 22: 111-6.

2. Katsas K, Mamalaki E, Kontogianni MD, et al.Malnutrition in older adults: Correlations with social, diet-related, and neuropsychological factors, Nutrition 2020; 71: 110640.

3. Wham CA, McLean C, Teh R, Moyes S, Peri K, Kerse N. The BRIGHT Trial: What are the factors associated with nutrition risk?, J Nutr Heal Aging 2014; 18: 692-7.

4. Damayanthi HDWT, Moy FM, Abdullah KL, Dharmaratne SD. Prevalence of malnutrition and associated factors among community-dwelling older persons in Sri Lanka. A cross-sectional study. BMC Geriatr 2018; 18: 199.

5. Maseda A, Diego-Diez C, Lorenzo-López L, López-López R, Regueiro-Folgueira L, Millán-Calenti JC. Quality of life, functional impairment and social factors as determinants of nutritional status in older adults. The VERISAÚDE study. Clin Nutr 2018; 37: 993-9.

6. Estrada A, Cardona D, Segura AM, Chavarriaga LM, Ordóñez J, Osorio JJ. Calidad de vida de los adultos mayores de medellín. Biomedica 2011; 31,492-502.

7. Khatami F, Shafiee G, Kamali K, et al.Correlation between malnutrition and health-related quality of life (HRQOL) in elderly Iranian adults. J Int Med Res 2020; 48(1): 030006051986349.

8. Hiramatsu M, Momoki C, Oide Y, et al. Association between risk factors and intensive nutritional intervention outcomes in elderly individuals. J Clin Med Res 2019; 11: 472-9.

9. Akın S, Ozer FF, Ertürk Zararsız G, et al. Validity of simplified nutritional appetite questionnaire for Turkish communitydwelling elderly and determining cut-off according to mini nutritional assessment. Arch Gerontol Geriatr 2019; 83: 31-6.

10.Dafsari FS, Bewernick B, Biewer M, et al. Cognitive behavioural therapy for the treatment of late life depression: Study protocol of a multicentre, randomized, observer-blinded, controlled trial (CBTlate). BMC Psychiatry 2019; 19: 423.

11. Ertan T, Eker E. Reliability, validity, and factor structure of the geriatric depression scale in Turkish elderly: Are there different factor structures for different cultures? Int Psychogeriatrics 2000; 12: $163-72$.

12. Güngen C, Ertan T, Eker E, Yaşar R, Engin F. Standardize mini mental test'in Türk toplumunda hafif demans tanısında geçerlik ve güvenilirliği. Türk Psikiyatr Derg, 2002; 13: 273-81.

13. Mollinedo Cardalda I, López A, Cancela Carral JM. The effects of different types of physical exercise on physical and cognitive function in frail institutionalized older adults with mild to moderate cognitive impairment. A randomized controlled trial. Arch Gerontol Geriatr 2019; 83: 223-30.

14. Aycicek GS, Çalıskan H, Ozsurekci C, et al. A reliable tool for assessing MCI and dementia: validation study of DemTect for Turkish population. Am J Alzheimer's Dis Other Dementiasr 2020; 35: 153331752094980.

15. Cho EH, Woo YJ, Han A, Chung YC, Kim YH, Park H. Comparison of the predictive validity of three fall risk assessment tools and analysis of fall-risk factors at a tertiary teaching hospital. J Clin Nurs 2020; 29: 3482-93.

16. Kawakami R, Murakami H, Sanada K, et al.Calf circumference as a surrogate marker of muscle mass for diagnosing sarcopenia in Japanese men and women. Geriatr Gerontol Int 2015; 15: 969-76.

17. Kretzer DC, Matos S, Von Diemen L, et al. Anthropometrical measurements and maternal visceral fat during first half of pregnancy: A cross-sectional survey. BMC Pregnancy Childbirth 2020; 20: 576.

18. Onyekwelu J, Nwankwo C. Significance of the difference in the estimates of glomerular filtration rate obtained using different models. Niger J Clin Pract 2019; 22: 258-64. 
19. Adıgüzel E, Acar-Tek N. Nutrition-related parameters predict the health-related quality of life in home care patients. Exp Gerontol 2019; 120: 15-20.

20. Krishnamoorthy Y, Vijayageetha M, Kumar Sg, Rajaa S, Rehman T. Prevalence of malnutrition and its associated factors among elderly population in rural Puducherry using mini-nutritional assessment questionnaire. J Fam Med Prim Care 2018; 7: 1429.

21.El Osta N, El Arab H, Saad R, et al. Assessment of nutritional status of older patients attending a tertiary hospital in Middle Eastern country. Clin Nutr ESPEN 2019; 33: 105-10.

22. Salminen KS, Suominen MH, Soini H, et al.Associations between nutritional status and health-related quality of life among longterm care residents in Helsinki. J Nutr Heal Aging 2019; 23: 474-8

23. Marinho R, Pessoa A, Lopes $M$, et al. High prevalence of malnutrition in Internal Medicine wards - a multicentre ANUMEDI study. Eur J Intern Med 2020; 76: 82-8.

24.Espinosa del Pozo PH, Espinosa PS, Donadi EA, et al.Cognitive Decline in Adults Aged 65 and Older in Cumbayá, Quito, Ecuador: Prevalence and Risk Factors. Cureus 2018; 10: e326910.

25. Tana C, Lauretani F, Ticinesi A, et al. Impact of nutritional status on caregiver burden of elderly outpatients. a cross-sectional Study. Nutrients 2019; 11: 281.

26. Tsutsumiuchi K, Wakabayashi H, Maeda K, Shamoto H. Impact of malnutrition on post-stroke cognitive impairment in convalescent rehabilitation ward inpatients. Eur Geriatr Med 2020; https: // doi. org/10.1007/s41999-020-00393-0

27. Adly NN, Abd-El-Gawad WM, Abou-Hashem RM. Relationship between malnutrition and different fall risk assessment tools in a geriatric in-patient unit. Aging Clin Exp Res 2020; 32: 1279-80. 